\title{
The Relevance of Transference during Medication Management: A Case of Erotized Transference
}

\author{
Helen C. Kales M.D. \\ Department of Psychiatry, University of Michigan \\ James Abelson M.D., Ph.D. \\ Department of Psychiatry, University of Michigan \\ Michelle B. Riba M.D. \\ Department of Psychiatry, University of Michigan
}

Follow this and additional works at: https://jdc.jefferson.edu/jeffjpsychiatry

Part of the Psychiatry Commons

Let us know how access to this document benefits you

\section{Recommended Citation}

Kales, Helen C. M.D.; Abelson, James M.D., Ph.D.; and Riba, Michelle B. M.D. (1998) "The Relevance of Transference during Medication Management: A Case of Erotized Transference," Jefferson Journal of Psychiatry. Vol. 14 : Iss. 1 , Article 6.

DOI: https://doi.org/10.29046/JJP.014.1.005

Available at: https://jdc.jefferson.edu/jeffjpsychiatry/vol14/iss1/6

This Article is brought to you for free and open access by the Jefferson Digital Commons. The Jefferson Digital Commons is a service of Thomas Jefferson University's Center for Teaching and Learning (CTL). The Commons is a showcase for Jefferson books and journals, peer-reviewed scholarly publications, unique historical collections from the University archives, and teaching tools. The Jefferson Digital Commons allows researchers and interested readers anywhere in the world to learn about and keep up to date with Jefferson scholarship. This article has been accepted for inclusion in Jefferson Journal of Psychiatry by an authorized administrator of the Jefferson Digital Commons. For more information, please contact: JeffersonDigitalCommons@jefferson.edu. 


\title{
The Relevance of Transference During Medication Management: A Case of Erotized Transference
}

\author{
Helen C. Kales, M.D., James Abelson, M.D., Ph.D., \\ and Michelle B. Riba, M.D.
}

\begin{abstract}
Forces existing in psychiatry may diminish the importance of psychotherapy training as psychiatrists are increasingly given the task of medication management. Psychotherapeutic relationships can be created in medication management settings, however, and the neglect of concepts such as transference could have deleterious consequences. The authors describe the case of a man with a traumatic brain injury referred for medication management who developed an erotized transference toward his female resident-physician. This case illustrates the concept that an understanding of transference is relevant to the setting of medication management.
\end{abstract}

The current climate in psychiatry is a challenging one for graduating residents as the very career they selected has changed before them during their residencies. Gabbard has described the "big chill" of managed care awaiting those leaving residency (1). In addition, some have argued that advances in biological psychiatry at times lead to the viewpoint of "biological reductionism" which in combination with the shaping of psychiatric treatment by economic forces could jeopardize psychotherapy training (2). If one is to believe the 'horror stories', graduating psychiatrists are faced with a future consisting of 'pill-pushing' and will have neither the time nor the financial incentives to reflect on the other components of the biopsychosocial model; Staton has written that future psychiatrists will need to be mainly biologically-, crisis-, and rehabilitation-oriented (3). It is conceivable that these constraints could cause concepts such as transference to become merely interesting sidelights to the general psychiatrist. If psychiatry finds itself "losing the mind" (4), what will be the consequences?

Even if our field moves towards an increasing proportion of time spent in the task of medication management in managed care settings, the neglect of concepts such as transference could still have deleterious consequences. Though the prevailing forces

Presented in part at Department of Psychiatry Grand Rounds, University of Michigan Medical Center, March 1996.

Please address correspondence to Dr. Helen C. Kales, Department of Psychiatry, University of Michigan, VAMC, Box 116A, 2215 Fuller Road, Ann Arbor, MI 48105 Telephone \#(313)7617926. 
may diminish the importance of these concepts in the training of psychiatrists, they surely will not prevent our patients from confronting us with forms of transference, nor will they prevent our countertransference responses. More likely, the potential changes in training would affect psychiatrists' ability to observe and understand these processes. It has been argued that psychotherapeutic relationships are created even in the setting of medication management (5). Book has described that noncompliance or difficulty taking medications may represent manifestations of transference (6). An understanding of transference should inform and enhance medication management, as the physician who is able to perceive and understand such conflicts around medications should be better able to manage their consequences. Some have argued that the "psychotherapeutically competent psychiatrist" will be able to manage the doctor-patient relationship created in the medication management setting more effectively (7).

The issues illustrated above were brought into sharp relief for the residentauthor of this paper (H.C.K.) as a third-year resident during a case where she was assigned to provide medication management. Though the patient himself was "assigned" only to the role of receiving medications, his unconscious revealed other compelling forces at work and he developed an erotized transference toward the resident which greatly impacted the nature and course of the treatment. Though there were also clearly idealized elements to this transference, the focus of this paper will be the erotization, given its increasing dominance during the treatment. Described primarily in the analytical literature, erotic transference refers to a mixture of erotic, sexual, reverential, romantic, and tender feelings (forming part of a positive transference) that a patient experiences toward the therapist $(8,9)$. Freud had described a strong form of erotic transference which he felt was resistant to analytic technique (10). Several authors have expanded on this concept, using the term erotized transference, to describe an exaggerated subspecies of erotic transference appearing early in treatment which is ego-syntonic, dependent, and demanding (11-13).

The patient described was seen for approximately one year and during this time, the resident was supervised for the first six months by one supervisor (M.B.R.) and following a rotation change, by a second supervisor (J.A.). We will be using this case to suggest and discuss the idea that even in a case where the primary problem may be a patient with organic pathology who is referred for a psychopharmacological evaluation, an understanding of transference is still relevant to treatment planning and treatment decisions. The case will be presented in three parts so that the reader can share and experience to some degree the complexity of this case as it unfolded for us.

\section{CASE PRESENTATION (DR. KALES)}

\section{Part One: Initial Evaluation}

Mr. B is a 51 year old male referred by the Physical Medicine and Rehabilitation Department (PMR) for evaluation of "disabling anxiety" and for medication management. The patient had a motor vehicle accident several years earlier resulting in loss of 
consciousness, a cervical fracture, bifrontal subdural hematomas, and residual evidence of a traumatic brain injury. Neuropsychiatric testing completed after the accident indicated that Mr. B had average intellectual functioning (VIQ $=102, P I Q=92$, FSIQ $=98$ ) which was thought to represent a decline from an estimated pre-traumatic level in the high-average range. Verbal abilities, thought to be a strength pre-morbidity, post-traumatically were characterized by tangentiality. Also present were mild to moderate impairments in long-term memory and planning, organization and problemsolving abilities (thought to reflect frontal lobe pathology). A lack of insight into the nature and degree of impairments on Mr. B's part was observed. Subsequent testing showed little change, with an IQ in the average range, verbal dysfluencies, impaired attention and concentration, mild memory impairment and deficits in planning/ organization. Mr. B continued to exhibit difficulties with novel situations, but was noted to learn and adapt well when he could utilize language or tap into prior experiences.

During outpatient follow-up in PMR over several years, referrals for psychiatric evaluation were evidently attempted but consistently refused by the patient. Other than a trial of low dose nortriptyline for insomnia prescribed by the patient's internist, Mr. B had not been treated with psychiatric medications. He had no history of substance abuse. When he finally appeared for psychiatric evaluation, he had recently returned to PMR for medical care after a period of absence. At the time of evaluation, Mr. B was receiving rehabilitation and vocational counseling from Dr. E, a neuropsychologist in PMR.

When I saw Mr. B for the psychiatric evaluation, he described feeling "worried all the time" and at times experiencing a "pressure on the heart ... a fight or fear response ... like you're being chased by the police." His heart would race for "hours," but there were no other accompanying symptoms. He felt "scared ... some people can sense impending death" and he wondered if his symptoms foretold something bad happening to someone. He had been told he was "not having a heart attack" when he had gone to an emergency room during an episode. Though he stated he experienced these symptoms during the interview, notably he never appeared overtly anxious or in pain. Mr. B told me "you're attractive and that's why I'm nervous ... I'm feeling much better just talking to you."

Mr. B was married with children, though he and his wife had been separated in the past. Prior to his accident, he had completed college and a Master's degree, but was working in another field until the time of the accident because he said he wasn't able to support himself in the area of his degree. He was now on disability. Mr. B's wife was college-educated and employed. During the evaluation, Mr. B was preoccupied with a daughter whom he described as "the apple of my eye" and he directly linked his anxiety to his concerns about this daughter.

Mr. B was a physically imposing male who appeared his stated age. He seemed to become very attached to me as the interview progressed, making statements like "you are a God-send" and "you are just what the doctor ordered." At the end of the interview, he seemed not to want to leave the office. His affect was labile, at times appearing anxious or angry but becoming "very happy" speaking me. Speech was increased in amount and generally of normal rate. However, occasionally Mr. B's speech would become slurred and he would have difficulty enunciating words. These episodes appeared related to times when Mr. B was experiencing strong emotions such as when he described his concerns about his daughter or his worries that something bad would 
happen to someone. Thoughts were coherent but tangential and at times disorganized with hints of paranoia. Given this thought pattern, it was often difficult to obtain precise descriptions of symptoms and their time course. He denied symptoms of a formal thought disorder, suicidal or homicidal ideation, or hallucinations. Cognitively, Mr. B had decreased short and long-term memory, somewhat decreased attention, intact concentration and concrete interpretations of proverbs. He refused to answer further cognitively-related questions stating that these questions were upsetting him.

Providers in PMR, Dr. M (his primary physician) and Dr. E (the neuropsychologist), indicated that in the past Mr. B had shown signs of paranoia and mistrust, at times appearing almost delusional, tangential, and grandiose, but had resisted seeing a psychiatrist. Idealizing his treators initially, he would later become very disappointed with them; in particular he had been very attached to a female resident, Dr. G, in their clinic. Mr. B had angrily dropped out of treatment due to his difficulties accepting his cognitive impairments; he had also left his wife at that time. He received care in numerous outside treatment settings for some time (at one point, Mr. B's insurance company had received bills from 25 different providers), but had returned to $\mathrm{Dr}$. $\mathrm{M}$ several weeks prior to our evaluation.

Following the evaluation, appointments were limited to twenty minutes weekly for medication management given that the patient was receiving counseling in PMR. It was discussed with Mr. B that sessions would be tapered back in frequency as he was stabilized on medications. During appointments, Mr. B gazed at me adoringly, brought items like pictures of himself with celebrities "to show he was important," and increasingly made reverential comments towards me (comparing me to heroines in movies). I responded that Mr. B seemed to be indicating that I was "important" to him and that likewise he seemed to wish to be seen as "important." Mr. B stated that he wished to be seen as worthy of my "attention as a woman." Calling between sessions, Mr. B stated he was anxious which he felt was relieved only by speaking to me. When limits were set with Mr. B regarding phone calls, he left letters in my mailbox praising my "insightfulness," describing his need for more time with me ("my whistle is unwhetted"), listing attributes he needed in a psychiatrist ("I need a woman who'll move her shoulder toward me so I can cry a little") and declaring me his "earth angel." After Mr. $B$ was seen in the clinic delivering a letter to the my mailbox (on a day when he did not have an appointment), my female supervisor (M.B.R., the first supervisor on the case) expressed concerns regarding his potential toward stalking. We decided it would be best to ask Mr. B to discontinue his letters to me.

After I asked to meet with his wife to gather further history, Mr. B stated, "I'll arrange that but I'm selfish and I want you to myself." I noted that meeting with his wife would be helpful for his treatment and he agreed. When I met with her, Mrs. B stated that Mr. B had a definite personality change after the accident with "anxiety, paranoia and mistrust," telling her at times their phone was "tapped." In the past, Mr. B had struck his daughters on occasion, but had "learned not to touch"; Mrs. B denied he had ever struck her. After the accident, Mr. B had possibly verbally threatened an insurance agent which had precipitated the initial suggestion that Mr. B see a psychiatrist. Mrs. B felt Mr. B had actually improved over the years in terms of his functioning and control of impulsivity. Mrs. B described her husband as "attached and clingy" with some people, wanting to "be special to them." She also revealed that prior to leaving treatment at the 
hospital, Mr. B had been evaluated by a private psychiatrist, but did not return after developing the idea that this doctor was in "cahoots" with the hospital.

\section{DISCUSSION—PART ONE}

Issues Discussed in Supervision

Chief among Mr. B's initial complaints were chest pressure and anxiety, which he seemed to feel when ruminating about emotional issues. Mr. B's anxiety did not appear classic for panic attacks given its pattern, duration (lasting hours) and the fact that although he stated he had these symptoms during the interview, he did not appear particularly distressed. Post traumatic stress disorder related to the car accident was also considered, however Mr. B had not experienced symptoms such as flashbacks, nightmares or hypervigilance. Symptoms of disinhibition, lability, tangentiality and paranoia were noted on interview. A portion of Mr. B's presentationcognitively, emotionally, and interpersonally_seemed clearly related to his frontal lobe damage. Frontal lobe syndromes can be characterized by impulsivity and decreased foresight (14), but such damage may occur in the context of pre-existing vulnerabilities. Little was known about this man's pre-morbid functioning in terms of vulnerability to anxiety, depression and affective lability, and perhaps most importantly, little was known about Mr. B's pre-injury character structure. At this point, nothing was known about his developmental history. One clue present was that he had been working far below his level of education. We were curious as to whether this was due to characterological issues, neurotic conflicts, family difficulties, problems in the job market or any other reason. The hint of paranoia in his presentation made us wonder about underlying delusional or schizotypal traits. The hint of excess energy and grandiosity in his presentation caused us to consider pre-existing vulnerability to bipolarity or cyclothymia.

\section{Resident's Perspective (Dr. Kales)}

The rapid development and fairly disinhibited expression of Mr. B's adoration toward me no doubt were at least partly attributable to his brain injury. But it was also noteworthy that he was not showing evidence of indiscriminate hypersexuality and disinhibition. In fact, in his wife's estimation, Mr. B had made considerable progress in his impulse control abilities in the years since the accident. It might be surmised therefore that by simply being an appropriately caring doctor who also happened to be female, I was tapping into something in this patient's psyche that elicited a particular kind of attention from him. Blum has described erotized transference as a demanding, persistent erotic transference where the more refractory cases have a lengthy history of impulsive and self-defeating behaviors (11). There were some hints that $\mathrm{Mr}$. B had developed similar attachments to prior care providers. I felt a pattern here could well reflect an interaction between his preexisting psychological structure and his organically-based disinhibition. 
Supervisor's Perspective (Dr. Riba)

The big question was, how worrisome was this? The resident expressed feeling perplexed at the rapidity of the transference's development, especially in the setting of medication management, but did not express feeling frightened. From early on, she had described responding to Mr. B's comments by acknowledging his strong feelings for her and noting that appointments were a place where he could express them; she also often described attempting to redirect those feelings toward his treatment. At the time, we felt that, given Mr. B's history of unstable relationships with doctors and his strong resistance to prior efforts to get him psychiatric help, the striking transference might be used to facilitate compliance with appropriate care. I did feel concerned, however, that these feelings in an impulsive patient could dangerously escalate and urged strict limit-setting in order to "contain" the transference.

\section{Treatment Course: The First Six Months (Dr. Kales)}

Several weeks after evaluation, Mr. B no longer complained of anxiety or the "pressure." He attributed this both to speaking with his daughter and to the "strong halo effect" he felt I exerted. While a mood stabilizer might likely have been helpful for Mr. B's tangentiality, grandiosity and lability, my supervisor and I questioned his ability to comply with one. Mr. B was started on risperidone $0.5 \mathrm{mg}$ HS for target symptoms of paranoia and suspiciousness approximately one month after evaluation. The dose was eventually increased to $2 \mathrm{mg}$. He was spottily compliant. Mrs. B noted that medication decreased the patient's "irritability and agitation," and Mr. B felt it helped his "sleep and thinking." However, he stated that " $2 \mathrm{mg}$ was overboard" and discontinued it. He refused to resume risperidone but agreed to take haloperidol, which was started at $1 \mathrm{mg}$ at HS.

Mr. B discontinued haloperidol after several weeks. At this appointment he cried as he described his brain as "shut down." Like his speech, he felt his thoughts were "stuttering" and he wanted his brain to "revive." When I reiterated that one of the purposes of the haloperidol was to organize Mr. B's thinking, he agreed to resume the medication. At the next appointment he revealed he had not, instead asking me to "be there all the time" to help his thinking and requesting a picture of me to keep. I asked Mr. B if he thought his requests might have to do with my upcoming vacation. He indicated that he was going to miss me and thought a picture might help. Mr. B also wore a suit which was too small to "illustrate" that he could not take haloperidol if it could cause weight gain.

Mr. B did eventually resume haloperidol and appeared more organized. He commented on my appearance frequently ("your eyes are too beautiful," "you are my beautiful nerd") and wondered about a "special relationship" with me. I acknowledged Mr. B's feelings, but noted that my role was to be his doctor. After several weeks, haloperidol was increased to $2 \mathrm{mg}$ as $\mathrm{Mr}$. B continued to be somewhat suspicious (particularly toward Dr. E with whom he didn't want me to communicate any longer). In total, Mr. B appeared compliant with haloperidol for approximately 2 months and indeed appeared much more organized and less suspicious.

Six months into treatment, Mr. B called "emergently" requesting my "philosophical 
endorsement" of a math class. At the next appointment, he elaborated: "I'm taking Haldol for you" and in return he wanted me to "show he was special" by "prescribing" a class (which PMR would usually coordinate). He spoke about how it was difficult for him to formulate his argument for the class in my presence where my "beauty and perfume overwhelmed" him. I noted that Mr. B often made comments about my "specialness" and wondered if he was asking me to reciprocate. Mr. B acknowledged this and stated that he wished that we could have a "special relationship" and therefore wished me to "exceed what you ordinarily would do for a patient." He felt he had expressed his love for me and wished for me to do the same. I noted that we could discuss his feelings but that I would not be able to grant his request. Mr. B became angry and stated he was "leaving." He later called to state that I had "broken his heart."

Several weeks later, Mr. B returned stating that I "had him hooked." Off haloperidol since his last appointment, he again demanded the "prescription" of the class to "establish trust." After supervision (with a new male supervisor, J.A.), I proposed an increase of appointment length to fifty minutes (as the transference appeared to be precluding stabilizing Mr. B on medications and was difficult to discuss in twenty minute sessions). Mr. B was initially very pleased, expressing "love" for me and the wish that I could be further involved in his life.

\section{DISCUSSION_PART TWO}

\section{Issues Discussed in Supervision}

At this point, we still had a limited understanding of Mr. B's inner life and developmental background, but we did now know that he could appear much more organized and less suspicious when on a neuroleptic. His wife indicated he improved in a variety of ways on this type of medication and there was also feedback from PMR that, while on haloperidol, Mr. B was better able to work with them on raising his level of functioning. Mr. B had a prior history of spotty compliance with care; his compliance now seemed to have gotten tied up with transference issues. Greenacre has noted that in some patients positive transference forms rapidly, but the transference becomes demanding and can exploit a sympathetic countertransference (15). Mr. B's initial, intense idealized transference may have helped engage him in treatment, allowing him to try the medications being prescribed, but now the transference was disruptive in the sense that his requests for special attention were escalating. Appropriate limit-setting was leading to acting out, rebelliousness, and non-compliance as his comments also became more erotized in their nature. Rappaport noted that patients with erotized transferences are angry and express this anger easily when the therapist does not fulfill all their demands (12).

\section{Resident's Perspective (Dr. Kales)}

Mr. B was allowed to continue to ventilate his feelings about "our relationship," but I felt it was important to continue to set limits with him about the boundaries of this relationship. I wondered if I should raise my level of concern about Mr. B's potential dangerousness. By offering an increased length of session, I hoped to 
increase Mr. B's trust and hopefully his compliance. Koenigsberg, discussing patients with borderline personality disorder, has stated that achieving medication compliance may require a more intensive psychotherapeutic relationship (16). I also considered that 'offering' him anything might be interpreted as a sign of specialness by Mr. B. Indeed this 'offer' to Mr. B might be considered a "partial transference gratification" (17). Would he be encouraged and raise the stakes? Would he respond to limit setting in more aggressive ways?

\section{Supervisor's Perspective (Dr. Abelson)}

As the new supervisor, I also felt that I had to be careful knowing that the prior female supervisor had expressed considerable worry about this patient's potential for sexual acting out. I noted however that the resident had communicated a strong sense of not feeling personally threatened by this patient and I sensed that she had been managing Mr. B's transference as well as it could be managed in a clinically productive way. So we decided to allow an intensification of the relationship, by going to full sessions from half sessions, hoping that the increased time could be used to reverse that growing sense that the transference might be now undermining treatment.

\section{Treatment Course: The Last Six Months (Dr. Kales)}

After several weeks, Mr. B again demanded an "endorsement" of a class to "increase trust" and "align on his side." I spoke with Dr. M who concurred that their department needed to coordinate Mr. B's educational requests. He would reiterate this to Mr. B. Mr. B continued to express the need for an indication of a "special" relationship. Mr. B also worried that I had told Dr. E that he was "giving me trouble" and that Dr. E would actively hinder his enrollment. I noted to Mr. B that after I had "frustrated" his request for the class, he seemed to feel he could no longer trust me. Mr. B stated if I would not do what he asked, he would see a woman psychiatrist who could also be his "friend." When I noted to Mr. B that he seemed to have a pattern of needing to "leave" people in anger (as with PMR), Mr. B stormed out of my office stating he was "never coming back."

A month later, Dr. M contacted me stating Mr. B wished to return. I indicated that Mr. B was welcome to return to treatment but would need to follow some ground rules (process educational requests appropriately, permit communication between providers and with his wife, and consider another medication trial). Dr. M was to tell Mr. B and have him call me. Mr. B called 3 months later, asking for "forgiveness." He asked, "Will you take me back as a patient?" He'd had a dream where I was a "vision wearing green" and felt it a premonition "beckoning him back."

During the six months after his return, Mr. B and I extensively discussed his departure from treatment (which he referred to as "our break-up"). Mr. B described me as a "proud woman" and stated that he "admired" me for "not dancing to his tune." Mr. B was amenable to the "ground-rules" with the exception of the communication issue. He was concerned others would "find out" he was "in love with" me, that "the two women" in his life (his wife and I) might would "sit down together and align" with 
information against him. Mr. B was reassured that his feelings toward me would be kept confidential from his wife. It was observed to Mr. B that he seemed to compartmentalize people to "protect" himself, keeping people "in the dark" about him. For example, despite seeing Mr. B on and off for a year, I noted that I still knew little about his family of origin. Mr. B reacted with surprise, stating "I'll need to trust you a lot more before I'll discuss that." I noted that open communication would benefit Mr. B and his goal of better functioning. Mr. B stated he still wished that I could "do something special" for him. When I noted that the relationship of a psychiatrist and a patient in fact was special because of the boundaries which created a different relationship than one had with "a friend," Mr. B appeared dumb struck and pleased.

Mr. B did agree to all the "ground rules" and we met jointly with his wife on several occasions. One month after his return, when I noted that I had been struck by how coherent, organized, and appropriate $\mathrm{Mr}$. B appeared, he revealed that he had decided to restart the haloperidol on his own ten days prior. He was very pleased that $I$ had noticed his improvement. In the subsequent four months with the combination of haloperidol and therapy, Mr. B. appeared better able to ward off his tendency to enact conflicts in an impulsive fashion, to discuss his transference with me and for the first time began to talk about issues and his family in a more personal manner. However, as my graduation and hence termination with him approached, Mr. B's erotization reescalated around the issue of "saying good-bye." He initially tried to "bargain" for continued contact with me after treatment. He comments became increasingly sexual in nature, speaking about wanting to give me " 1,000 kisses" until the end of treatment and of wanting to take me away to a "ranch" where I would have his children. I noted to him that these comments appeared related to his pain at the upcoming loss of the therapeutic relationship. He was able to discuss how he also felt pain when Dr. G had graduated but was eventually able to "get over it." Mr. B was introduced to his new resident one month prior to the end of treatment in an effort to smooth the transition. Impressively at this meeting, he was able to put his feelings into words and tell her, "I don't know what kind of patient I'm going to be for you, I'm having a hard time with Dr. Kales leaving." Mr. B did continue on haloperidol and was amenable to a trial of a mood stabilizer, however due to a baseline low platelet value, this trial was deferred pending a Hematology consult. Mr. B did cancel his last two appointments with me, appearing to need to gain some control over termination, but was able to speak with me on the phone stating he had a hard time saying "good-bye." Mr. B is currently in follow-up with his new resident physician.

\section{DISCUSSION-PART THREE}

Issues Discussed in Supervision

Our diagnosis of this patient is that of a personality change due to a traumatic brain injury, as Mr. B appears to have had a marked change in personality style from his prior level of function, as well as perhaps an exacerbation of previous character pathology (18). Mr. B becomes paranoid and disorganized but never otherwise overtly psychotic. He appears less suspicious and more organized with a neuroleptic but still becomes labile, tangential, grandiose, and impulsive at times of stress. We continue to wonder about the effect that a mood stabilizer would have. 
My countertransference response was to feel sympathetic toward, but at times exasperated and angered by Mr. B. I felt supported by frequent communication with Mr. B's other providers which minimized splitting and diminished the sense that the I was alone in dealing with Mr. B's strong transference toward me. It was helpful to acknowledge my countertransference in supervision, while setting appropriate limits with the patient. Mr. B reacted to these limits by acting out in a number of ways, yet ultimately returned to treatment praising me for not "dancing to his tune." It is my thought that perhaps Mr. B returned as he was reassured that destructive impulses were met not only with limits but with the sense that treatment would not be destroyed by provocative behavior. By providing a consistent therapeutic environment in addition to haloperidol which decreased his suspiciousness, I believe that Mr. B's trust was built to the extent that he could better discuss and process his feelings and impulses even as the loss of termination loomed. Loss has been noted as a significant theme in many cases of erotized transference (19) and Mr. B's improved functioning enabled us to better process this. Though Mr. B did cancel the last two appointments, he was able to continue in treatment with a new resident; this is highly significant given Mr. B's history of fleeing treatment settings.

\section{Supervisor's Perspective (Dr. Abelson)}

An interesting development after Mr. B's return to treatment was his decision to resume haloperidol. It has been argued that medication can serve as a transitional object creating a continuous symbolic relationship with the psychiatrist (6). It is possible that Mr. B's resumption of haloperidol was a symbolic further acting out of his erotized transference and also served as a transitional object as termination approached.

\section{CONCLUSION}

In presenting this patient, we have attempted to show that even in a case where the primary psychiatric problems are likely secondary to a traumatic brain injury and the treatment intervention is primarily medication, treatment may be difficult without attention to transference. Mr. B has the good fortune to have insurance coverage which has not limited his access to psychiatric care. We would seriously question whether this patient could be adequately treated in a 'managed' short-term framework. It is our hypothesis that he would likely permanently leave treatment or continue to reenact the erotized transference in new settings; Rappaport notes that sending the patient away may merely create another traumatic experience for the patient and does not guarantee that the patient will not erotize new treatment relationships (12). Mr. B has a history of dropping out of medical treatment only to seek care in numerous other settings, having utilized greater resources as evaluations and procedures were repeated. It would appear that Mr. B takes his transference with 
him wherever he goes, and that ultimately improvement in his functioning in both the medical and psychiatric settings may be dependent upon either his resolution of underlying conflicts, or at least an adequate understanding and management of them by his care providers. In summary, we have presented a case which we feel illustrates that an understanding of transference is relevant to the setting of medication management.

\section{REFERENCES}

1. Gabbard GO: The big chill: the transition from residency to managed care nightmare. Academic Psychiatry 1992; 16:119-126.

2. Lewis JM: Swimming Upstream: Teaching and Learning Psychotherapy in a Biological Era. New York, Brunner/Mazel, 1991.

3. Staton D: Psychiatry's future: facing reality. Psychiatric Quarterly 1991; 62:165-176.

4. Reiser MF: Are psychiatric educators "losing the mind"? Am J Psychiatry 1988; 145:148153.

5. Goldhamer PM: Psychotherapy and pharmacotherapy: the challenge of integration. Can J Psychiatry 1983; 28:173-177.

6. Book HE: Some psychodynamics of non-compliance. Can J Psychiatry 1987; 32:115-117.

7. Mohl PC, Lomax J, Tasman A et al: Psychotherapy training for the psychiatrist of the future. Am J Psychiatry 1990; 147:7-13.

8. Person ES: The erotic transference in women and in men: differences and consequences. J Am Acad Psychoanal 1985; 13:159-180.

9. Book HE: The "erotic transference": some technical and countertransferential difficulties. Am J Psychother 1995; 49:504-13.

10. Freud S: Observations on transference love. Standard Edition, Vol. 12, 1915.

11. Blum HP: The concept of erotized transference. J Am Psychoanal Assoc 1973; 21:61-76.

12. Rappaport EA: The management of an erotized transference. Psychoanal Quart 1956; 25:515-529.

13. Greenson RR: The Technique and Practice of Psychoanalysis. New York, International Universities Press, 1967.

14. Cummings JL: Neuropsychiatry and behavioral neurology, in Comprehensive Textbook of Psychiatry, 6th edition. Edited by Kaplan HI and Sadock BJ. Baltimore, Williams and Wilkins, 1995.

15. Greenacre P: General problems of acting out. Psychoanal Quart 1950; 19:455-467.

16. Koenigsberg HW: Combining psychotherapy and pharmacotherapy in the treatment of borderline patients, in American Psychiatric Press Review of Psychiatry, Volume 12. Edited by Oldham JM, Riba MB, and Tasman A. Washington DC, American Psychiatric Press, 1993.

17. Gabbard GO: On love and lust in erotic transference. J Am Psychoanal Assoc 1994; 42:385-403.

18. Diagnostic and Statistical Manual of Mental Disorders, 4th ed. Washington, DC: American Psychiatric Association, 1994.

19. Kotze B, Meares R: Erotic transference and a threatened sense of self. Br J Med Psychol $1996 ; 69: 21-31$. 